\title{
Economic Growth - Unemployment Nexus in South Africa: VECM Approach
}

\section{Oatlhotse Madito}

University of South Africa, Department of Economics

Email:opmadito@yahoo.com

\section{John Khumalo}

Department of Economics, University of South Africa, South Africa P.O. Box 392, UNISA 0003, South Africa

Email: khumamj@unisa.ac.za

\section{Doi:10.5901/mjss.2014.v5n20p79}

\begin{abstract}
This study analyses unemployment - economic growth relationships and tests for any long-run relationship for the period 1967Q1 to 2013Q4. Due to the dynamic nature of the inter-relationships, the error correction is performed in order to find the speed at which growth of gdp adjusts to shocks in employment/unemployment in South Africa. The quality properties of data used reveal that such data does not contain correlation and hence the variables are integrated of order zero. The Johansen cointegration test revealed about four cointegrating vectors, while the model identification showed the South African growth model can be uniquely identified. This was done by imposing restrictions on the estimated coefficients. The vector error correction (VECM) method was used to test for short-run dynamics and the results showed that about 62 percent of economic growth is corrected each quarter. These overall results show that there is a negative relationship between economic growth and unemployment in South Africa.
\end{abstract}

Keywords: Economic growth, Unemployment, VECM, South Africa

\section{Introduction}

Unemployment and slow growth continues to be two of the major challenges facing every country regardless of the state of their economic and social development. The rate of unemployment has been relatively high at least since the 1980s, on the other hand the periods of unsteady growth has also been identified as the major driver that led to an increase in the rate of unemployment over the years. While the level of unemployment affects the rate of GDP-Growth, it also serves as an indicator of the country's state of the economy as it indicate how well the economy utilizes its resources. Vast of literature exist on the relationship between GDP-growth and unemployment; however, various economists and policy makers still have contradictory views on the significance and the direction of the relationship. South Africa faces a number of challenges with respect to effective and sustainable economic growth since the extent to which economic growth exists is mainly determined by changes in employment, output, inflation, interest rates and other macroeconomic variables that have an indirect impact on GDP such as disposal income and household expenditure.

The problem of high unemployment and slow growth is not only faced by developing countries. At some point, developed countries have also been subject to the two fundamental macroeconomic problems. As indicated by Abel et al (2008) the difference between developed nations and developing nations is that developed nations have at some point in their history experienced extended periods of rapid economic growth but that the poorer nations either have never experienced sustained growth or have had periods of growth offset by periods of economic decline.

The relationship between economic growth and unemployment is different from that of economic growth and employment which is positively related. In other words it is assumed that an increase in gross domestic product (GDP) or economic growth leads to a decrease in the rate of unemployment. Contrary to unemployment, an increase in GDPgrowth leads to an increase in the level of employment indicating a positive relation between GDP-growth and employment. However, assuming a direct link between economic growth and unemployment is not necessarily correct in reality based on the assertion that employment will rise only if economic growth rates exceed productivity gains (potential output). Expressed differently, in the long run the unemployment rate will only fall if GDP growth exceeds the combined growth rates of the labor force and productivity (Levine, 2013). 
Economic growth occurs even though the level of employment is low. Such growth in the economy occurs as a result of increase in the capital intensive methods of production. This method of production has a positive effect on GDPgrowth and a negative impact on the level of employment. Fourie and Burger (2009) suggest that the use of more capital and technology intensive methods of production can cause higher growth accompanied by stagnation or even a decline in the level of employment raising concerns that technological innovations is the major contributor of jobless growth in the economy.

Figure 1: Employment - GDP trends in South Africa

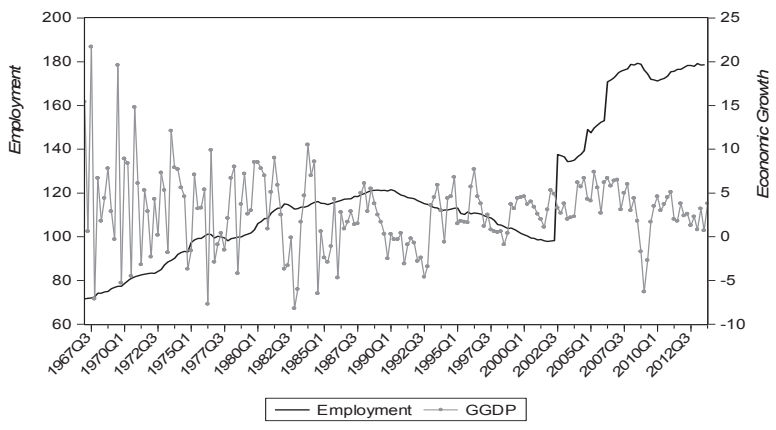

For the past three decades (1980-2010) the growth rate in South Africa's economy reached a maximum $6.6 \%$ and unemployment rate was at a minimum of $9.2 \%$ in 1980. Since 1980, South Africa has been inconsistent in terms of sustaining economic growth above $6.6 \%$, the trend in the business cycle has in most cases been characterized by downswings and most notably, the decline which lasted for about five years from 1988 to a record $-2.14 \%$ in 1992

Prior 1994, unemployment was a very serious issue given the political conditions in South Africa at the time. Unemployment rate showed a long term rise from $9.2 \%$ in 1980 to $22.9 \%$ in 1994 before it eventually declined to $16.7 \%$ in 1995. Since a rise in unemployment means that there is a decrease in employment as the two are synonyms. A decrease in employment does not only push community into poverty but also leads to decreased productivity. This remains a problem in the sense that even when the economy experienced growth from 1985 to 1988, the level of unemployment continued to rise. The effects of political instability at the time can be linked to the performance of the South African economy when GDP-growth was actually negative for the first three years of the 1990s. Most notably, in 1992 economic growth in South Africa was -2.14 percent which still hold the record as the country's lowest growth rate in almost 20 years.

Inflation on the other hand cannot be ignored as it plays a very crucial role in an economy. South Africa has experienced a relative increase in inflation although on average it has shown a decline. Figure 2 below depicts historical pattern of inflation and economic growth in South Africa. The two show that there has been a negative relationship between inflation and economic growth. South Africa has not experienced a huge growth that could result into high inflation. Inflation was relatively low in the late 1960s until the early 1970s although it showed a rising trend till the late 1970s. It entered into a double - digit in those years but later started showing a decline. The 1980s were characterized by high, but relatively stable rates of inflation ranging from 11.5 to $18.6 \%$. The average inflation rate for the decade was $14.7 \%$. Inflation subsided significantly in the early part of the 1990s. After peaking in 1986, the rate of inflation began decreasing and in 1993 it dropped to beneath $10 \%$. It subsequently decreased further to $5.2 \%$ in 1999. On average, consumer prices rose by $9.3 \%$ during the 1990 s. 
Figure 2: GDP - Inflation movements in South Africa

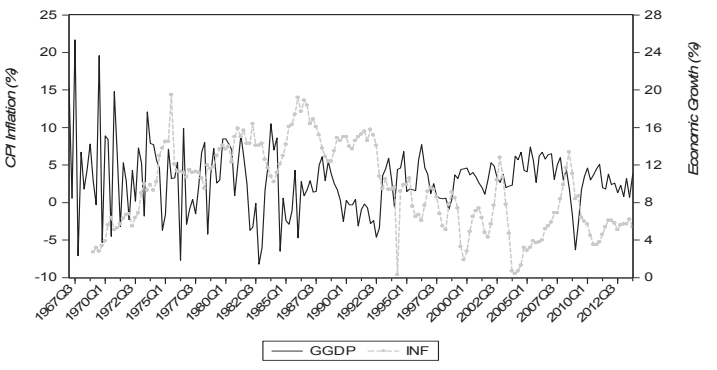

Economic growth on one hand had shown a non-stable scenario and in some instances averaging negatives for some years. The most notable instance was during the global financial crisis that saw economic growth being recorded at $-1.7 \%$ in the fourth quarter of $2008,-6.3 \%$ in the first quarter of 2009 and $-2.7 \%$ in the second quarter of 2009 . The economy was able to record a positive figure in the third quarter on 2009, although this figure was below the projected growth. Such low growth has seen inflation increasing marginally while at the same time unemployment was rising steadily.

\section{Review of Literature}

Various studies have been conducted on the link between economic growth and unemployment. According to Andrei et al (2009) the correlation between real GDP growth and unemployment is essential for policy makers in order to obtain a sustainable rise in living standards. Mohr and Fourie (2008) examines some of the fundamental causes or sources of long-run economic growth and suggest that sources can be grouped into two broad categories namely; supply factors (refers to those factors which causes an expansion in production capacity) and demand factors (refers to adequate and growing demand for goods and services produced), furthermore, they further suggest that both factors are necessary for sustainable economic growth.

Mahmoud (2012) used an application of okun's law to study the relationship between economic growth and unemployment in Arab countries and the findings of the study revealed that although a positive relationship exist between the two variable, the high rates of economic growth and the decline in the unemployment rate do not confirm the existence of strong relationship between GDP-growth and unemployment. A similar study was conducted by Muhammad (2013) using Hodrick-Prescott filter ${ }^{1}$ and least square method and it was found that a one percent rise in the rate of unemployment was followed by a decline of 0.3 percent on real GDP-growth indicating the existence of a relatively weaker relationship between the two variables particularly in developing countries.

A study conducted by Özel (2013) hold similar views as Mahmoud (2012) however, this study was based on data collected from 7 industrialized countries (G7) used to examine the correlation between unemployment and GDP-growth for pre and post-recession period. The results revealed that Productivity and GDP-growth had a significant impact on the reduction of unemployment prior to the crises. However, the results had an insignificant effect after the crises as GDPgrowth had a decreasing effect on unemployment. In addition, Rosoiu (2014) examined the relationship between GDPgrowth and unemployment in the USA from 1977-2011 and the results exhibited a positive link between the variables and the study also suggested that the financial crisis was fundamental on the relation between these two variables. Nonetheless, Cashell (2009) emphasize that there is evidently a strong link between the rate of economic growth and changes in the unemployment rate.

Doğan (2012) investigated the link between macroeconomic variables and unemployment using a Vector Autoregressive (VAR) method and the results of the study focused mainly on the effect of GDP-growth and inflation on the rate of unemployment. The findings showed that the link between the variables was consistent with okun's law and Phillips curve theory. VAR results confirmed the existence of a negative relationship between GDP-growth and unemployment and positive link between inflation and unemployment. Conversely, Hussain (2012) examined the relationship between GDP-growth and unemployment using a Vector Error Correction Model (VECM) and the significant positive coefficient of unemployment, labor and capital indicated a long run positive relationship with economic growth.

${ }^{1}$ The Hodrick-Prescott (HP) filter is a commonly used tool in macroeconomics for separating the long run trend in a data series from short run fluctuations. 
Consideration of structural changes in the economy is essential when analyzing the dynamics of economic variables as evidenced by Özel (2013) study that the behaviour of economic variables varies based on the events that occurred prior or post structural change in the state of the economy. Furthermore, Karanasou and Sala (2010) examined the determinants of unemployment in Australia and the results concluded that the reasons behind unemployment differ according to period investigated. As such, this study also considers some of the major historical and structural changes which had an impact on the link between GDP-growth and other exogenous variables included in the model. This approach stems from Özel (2013) view that differences in the economic structures of countries reflect upon the link between GDP-growth and unemployment to a great extent. In addition, Lee (2000) found that the real effects of economic growth on employment are that the coefficients are considerably different across countries, possibly due to the rigid circumstances of the labour markets. Several studies have been undertaken to understand the fundamental relationship between economic growth, unemployment and other macroeconomic variables; however, the confusion still remains on the significance and direction of the relationship among these fundamental macroeconomic variables.

\section{Research Method}

The paper uses the Vector Error Correction model (VECM) to determine the effect of employment on economic growth using the quarterly data from 1967 to 2013. The general dynamic nature of the econometric model takes the VAR form below:

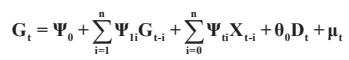

Where, $G_{t}$ is a vector of endogenous variables at quarter $t, X_{t-i}$ represents the set of all explanatory variables to be included in the model and their lags. Such variables include inflation and disposable income. $D_{t}$ in the model represents the dummies for establishment of any structural breaks in the system with the specified period. $\mu_{\mathrm{t}}$ on the other hand is the white noise error term. The model above represents the long run relationships and hence a VECM specified below in order to capture the short-run dynamics of variables in the system.

$$
\Delta \mathbf{G}_{\mathrm{t}}=\boldsymbol{\beta} \mathbf{D}_{\mathrm{t}}+\sum_{\mathrm{i}=1}^{\mathrm{k}-1} \boldsymbol{\Omega}_{\mathrm{i}} \Delta \mathbf{Y}_{\mathrm{t}-\mathrm{i}}+\Phi \mathbf{Y}_{\mathrm{t}-1}+\boldsymbol{\Omega}_{\mathrm{k}-1} \mathbf{Y}_{\mathrm{t}-\mathrm{k}+1}+\boldsymbol{\pi}_{\mathrm{t}}
$$

Where matrix $\Omega=\boldsymbol{\alpha} \cdot \boldsymbol{\beta}^{\prime}$ (thus $\boldsymbol{\Omega}$ is decomposed into two matrices of dimensions [ $\mathrm{n} \times \mathrm{r}$ ], and $\mathrm{r}$ is the number of cointegrating vectors), $\alpha$ is a matrix of adjustment coefficients or the loading matrix and contains the short run dynamics while $\beta$ is the matrix containing the long run equilibrium relationships or long run coefficients.

\section{Analysis and Research Findings}

The dynamic nature of the VECM implies that any discrepancies are fully corrected, including the unit root if available. But since VECM is a form of the VAR, then some diagnostics have to be conducted on the data to determine the data quality. These include autocorrelation and stationarity tests. Figure 3 below presents the autocorrelation results for the variables under consideration.

\begin{tabular}{|c|c|c|c|}
\hline GGDP & INFLATION & INCOME & EMP \\
\hline Autocorrelation & Autocorrelation & Autocorrelation & Autoc orrelation \\
\hline 垱 & & 5 & i! \\
\hline 沪 & 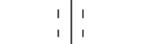 & (4) & 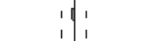 \\
\hline i! & & 10 & \\
\hline ii & & 15 & 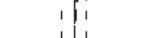 \\
\hline ili & i) & ii & is \\
\hline id & if & ib & 1 \\
\hline 15 & i) & 15 & i) \\
\hline if & 14 & 1 & 他 \\
\hline 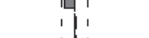 & 1 & שי & iा! \\
\hline ili & 1 & if i i & is \\
\hline 101 & 111 & 1대 1 & 11 \\
\hline
\end{tabular}

Figure 3: Correlograms of GDP and other variables 
The results from the autocorrelation indicate that there is no evidence of autocorrelation in the variables hence stationary. The results of group stationarity are presented in table 1 below

Table 1: Group unit root test

Series: GGDP, GEMP, GYD, INF

\begin{tabular}{|c|c|c|c|}
\hline Method & Statistic & Cross-sections & Obs \\
\hline \multicolumn{4}{|c|}{ Null: Unit root (assumes common unit root process) } \\
\hline Levin, Lin \& Chu t* & $-28.6432^{* * *}$ & 4 & 675 \\
\hline \multicolumn{4}{|c|}{ Null: Unit root (assumes individual unit root process) } \\
\hline Im, Pesaran and Shin W-stat & $-26.4915^{* \star *}$ & 4 & 675 \\
\hline ADF - Fisher Chi-square & $347.479^{* * *}$ & 4 & 675 \\
\hline PP - Fisher Chi-square & $347.776^{* * *}$ & 4 & 675 \\
\hline
\end{tabular}

*** indicates significance at $1 \%$ level

The results show that the economic growth, inflation, disposable income and employment are all integrated of order one. This calls for establishment of long-run relationship, which was conducted through the Johansen test shown below:

Table 2: Number of Cointegrating Relations by Model

\begin{tabular}{lccccc}
\hline \multicolumn{1}{c}{ Data Trend: } & None & None & Linear & Linear & Quadratic \\
\hline \multicolumn{1}{c}{ Test Type } & No Intercept & Intercept & Intercept & Intercept & Intercept \\
& No Trend & No Trend & No Trend & Trend & Trend \\
Trace & 4 & 4 & 4 & 4 & 4 \\
Max-Eigenvalue & 4 & 4 & 4 & 4 & 4 \\
\hline
\end{tabular}

The results above indicate that there are at least four cointegrating vectors in the model. This suggests that each variable is treated as an endogenous variable. Due to the existence of long-run relationship, the short-run dynamics could occur prompting us to determine the speed at which such shocks can be corrected.

\subsection{VECM results}

The validity of the VAR/VECM results depends on whether the VAR/VECM model is stable or not. In an event such stability condition is not fulfilled, the results could be misleading and hence inaccurate inference. The stability test is given below.

Figure 4: Inverse Roots of AR Characteristic polynomial

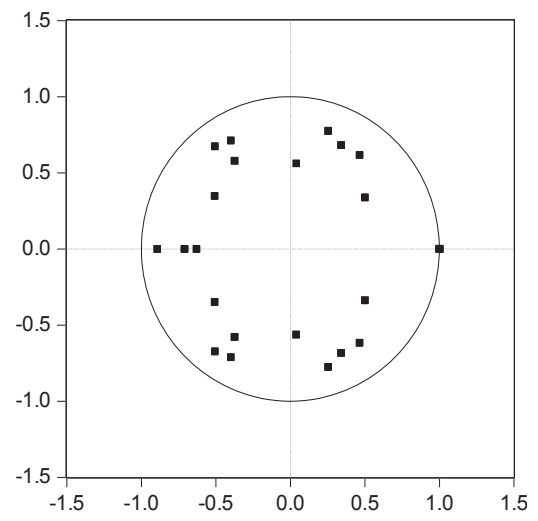

It can be seen that none of the points lies outside the circle, suggesting that our VAR/VECM model is stable and the results obtained would be valid. Table 3 below presents the VECM results pertaining to the error correction. 
Table 3: VECM test results

\begin{tabular}{cccc}
\hline Error Correction: & $D(G G D P)$ & $D(G E M P)$ & $D(G Y D)$ \\
\hline CointEq1 & -0.617735 & 0.279347 & 0.023147 \\
& $(0.14282)$ & $(0.14049)$ & $(0.13998)$ \\
& {$[-4.32515]$} & {$[1.98839]$} & {$[0.16536]$} \\
CointEq2 & 0.347254 & -1.034149 & -0.170758 \\
& $(0.23482)$ & $(0.23098)$ & $(0.23014)$ \\
CointEq3 & {$[1.47881]$} & {$[-4.47719]$} & {$[-0.74197]$} \\
& -0.582176 & -0.187634 & -0.565081 \\
& $(0.20872)$ & $(0.20531)$ & $(0.20456)$ \\
& {$[-2.78925]$} & {$[-0.91390]$} & {$[-2.76237]$} \\
\hline
\end{tabular}

The VECM results above reveal that about 61 percent of the disequilibrium is corrected each quarter by changes in economic growth in South Africa. This is warranted by the coefficient -0.617735 . The vector error correction (VEC) suggests the validity of the equilibrium relationship, indicating the existence of market forces that operate to restore long - run equilibrium after an economic shock. The results of this study are in line with what Mosikari (2013) in his paper found. There is a negative strong relationship between unemployment and economic growth in South Africa.

\section{Conclusions}

The paper attempts to test the speed at which economic growth in South Africa adjusts if there is a short- run shock in the macro - variables using the data that covers the span 1976 first quarter to 2013 fourth quarter obtained from the South African Reserve Bank (SARB) as well as Statistics South Africa. As a precaution to quality data, tests such as autocorrelation were conducted on economic growth, proxied by growth of gdp, inflation (proxied by cpi), employment and disposable income. Such variables did not provide any evidence of autocorrelation and were found to contain no unit root. The fact that all variables were integrated of order zero proved the existence of long - run relationships amongst them and required the analysis of the short-run dynamics in the model. The cointegration test showed that there were at least four cointegrating vectors, with each equation being identified by imposing the restrictions. The economic growth forecast shows a Theil inequality coefficient of 0.55 , which is very close 1 , suggesting that such forecast method applied may not be appropriate and that other methods will have to be explored in order to the give near-gdp forecast.

\section{References}

Abel, A.B., Bernanke, B.S. \& Croushore, D. (2008). Macroeconomics. Boston: Pearson Education, Inc.

Andrei, D.B., Vasile, D., \& Adrian, E. (2009). The correlation between unemployment and real GDP growth: A study case on Romania. Accessed 20 April 2014, available at http://steconomice.uoradea.ro/anale/volume/2009/v2-economy-and-business-administration/ 53.pdf

Cashell, B.W. (2009). Unemployment and Economic Recovery. Congressional Research Service. Federal Publications.

Doğan, T.T. (2012). Macroeconomic Variables and Unemployment: The Case of Turkey. International Journal of Economics and Financial Issues, 2(1): 71-78.

Fourie, F., \& Burger, P. (2009). How to think and reason in macroeconomics. Cape Town: Juta \& Co Ltd.

Hussain, T., Siddiqi, M.W., \& Iqbal, A. (2010). A Coherent Relationship between Economic Growth and Unemployment: An empirical evidence from Pakistan. International science index, 4 (3): pp. 956-963.

Karanassou, M., \& Sala, H. (2010). Labour market dynamics in Australia: what drives unemployment? The Economic Record, 86 (273), pp. $185-209$.

Lee, J.M. (2000). The robustness of Okun's law: evidence from OECD countries. Journal of Macroeconomics, pp. 22 (2), pp. 331-356.

Levine, L. (2013). Economic Growth and the Unemployment Rate. Congressional Research Service. Federal Publications.

Mahmoud, A.A., \& Mohammed, AR. 2012. The relationship between unemployment and economic growth in Jordan and some Arab countries. World Applied Sciences Journal, 18 (5), pp. 673-680.

Mosikari, T.J. (2013). The effect of unemployment rate on gross domestic product: Case of South Africa. Meditteranean Journal of Social Sciences, 4(6), pp.429-434.

Özel, H.A., Sezgin, F.H., \& Topkaya, Ö. (2013). Investigation of Economic Growth and Unemployment Relationship for G7 Countries Using Panel Regression Analysis. International Journal of Business and Social Science, 4 (6), pp. 163-171.

Roșoiu, I., and Roșoiu, A . (2014). The relation between unemployment rate and economic growth in USA. International Journal of Economic Practices and Theories, 4 (2), pp. 162-167. 